\title{
Synthesis and Properties of Biobased Epoxy Resins. Part 1. Glycidylation of Flavonoids by Epichlorohydrin
}

\author{
HÉLÈNE NOUAILHAS, ${ }^{1}$ CHAHINEZ AOUF, ${ }^{2,3,4}$ CHRISTINE LE GUERNEVE, ${ }^{2,3,4}$ SYLVAIN CAILLOL, ${ }^{5}$ BERNARD BOUTEVIN, ${ }^{5}$ \\ HÉLÈNE FULCRAND ${ }^{2,3,4}$ \\ ${ }^{1}$ Innobat, Cap Alpha, Avenue de I'Europe, 34830 Clapiers, France \\ ${ }^{2}$ INRA, UMR1083 Sciences Pour I'Oenologie, F-34060 Montpellier, France \\ ${ }^{3}$ Montpellier SupAgro, UMR1083 Sciences Pour I'Oenologie, F-34060 Montpellier, France \\ ${ }^{4}$ Université Montpellier I, UMR1083 Sciences Pour I'Oenologie, F-34060 Montpellier, France \\ 5Institut Charles Gerhardt, UMR CNRS 5253, Equipe Ingénierie et Architectures Macromoléculaires, ENSCM, 8 rue de I'Ecole \\ Normale, 34296 Montpellier Cedex 05, France
}

Received 2 November 2010; accepted 28 February 2011

DOI: $10.1002 /$ pola.24659

Published online 28 March 2011 in Wiley Online Library (wileyonlinelibrary.com).

\begin{abstract}
Biobased epoxy resins were synthesized from a catechin molecule, one of the repetitive units in natural flavonoid biopolymers also named condensed tannins. The reactivity of catechin toward epichlorohydrin to form glycidyl ether derivatives was studied using two model compounds, resorcinol and 4-methylcatechol, which represent the $A$ and $B$ rings of catechin, respectively. These model molecules clearly showed differences in reactivity upon glycidylation, explaining the results found with catechin monomer. The reaction products were characterized by both FTIR and NMR spectroscopy and chemical assay. The glycidyl ether of catechin (GEC) was successfully cured in various epoxy resin formulations. The GECs thermal properties
\end{abstract}

showed that these new synthesized epoxy resins displayed interesting properties compared to the commercial diglycidyl ether of bisphenol A (DGEBA). For instance, when incorporated up to $50 \%$ into the DGEBA resin, GEC did not modify the glasstransition temperature. Epoxy resins formulated with GEC had slightly lower storage moduli but induced a decrease of the swelling percentage, suggesting that GEC-enhanced crosslinking in the epoxy resin networks. (C) 2011 Wiley Periodicals, Inc. J Polym Sci Part A: Polym Chem 49: 2261-2270, 2011

KEYWORDS: polyphenols; recycling; renewable resources; resins; thermoplastics
INTRODUCTION In the field of green chemistry development, scientists, and especially chemists, are facing new stakes and have to deal with new constraints to answer to increasing needs in terms of food, energy, clean water, health, cosmetics, and transport of a growing world population in a sustainable development context. Current chemical emphasis is based on oil derivatives, but fossil resources are limited, and their prices are volatile. Therefore, global aims were set for an increase of use of renewable resources by chemicals companies. As a consequence of new regulations based on European directives focused on reduction wastes and pollutants volume ${ }^{1-4}$ substitutions have to be found for a large number of carcinogen, mutagen, and reprotoxic (CMR) classified substances. ${ }^{5}$ Some of these substances are constituents of widely used plastics. Among them, bisphenol A (BPA), which is classified as CMR R3, is one of the main components of epoxy resins.

Commercialized for more than 50 years, BPA is the most common phenol derivative used in epoxy resin formulations to produce adhesives, laminates, structural composites, pro- tective coatings, and many other products. BPA-based resins are also encountered in human health applications such as filling materials or sealants in dentistry. However, these polymers are sensitive to hydrolysis and leaching of BPA leading to widespread human exposure as revealed by numerous studies. $^{6-10}$ Moreover, high BPA levels in various human fluids and tissues have been detected, which can be responsible for health damages. ${ }^{11-14}$

Recent awareness on BPA toxicity combined with the limitation and high cost of fossil resources implies necessary changes in the field of epoxy resins. Major issues are to find both alternative to the typical synthesis route for epoxy resins and substitutes for BPA. In this sense, Cheng described the synthesis of a novel epoxy resin based on a polyaromatic phenolic compound synthesized from resorcinol and acetone with higher thermal resistance than standard epoxy resin based on diglycidyl ether of bisphenol A (DGEBA). ${ }^{15}$

New requirements for increased recycling have prompted other studies on the use of renewable resources such as 
wood derivatives as substitutes for BPA allowing reduced waste production. Thus, epoxy resins were synthesized from methanol soluble lignin extracted out of unused bamboo. ${ }^{16}$ Other teams have developed wood-based epoxy resins synthesized by a two-step process from wood powder: liquefied wood was obtained by reacting wood powder with resorcinol and then the glycidyl etherification of liquefied wood was conducted with epichlorohydrin. ${ }^{17,18}$ The purpose of the latter work was a wood valuation and not a study of the reactivity of hydroxyl groups present in wood compounds toward epichlorohydrin. Indeed, the wood powder was used without any further purification and hydroxyl groups present in liquefied wood can come from various wood components such as cellulose, lignin, and polyphenols. Wood tannins were also extensively studied by Pizzi and coworkers in formo-phenolic resins. Tannins were reacted with formaldehyde and with formaldehyde substitutes, such as glyoxal, in wood adhesives formulations. ${ }^{19-22}$

Polyphenols, and more specifically condensed tannins, extracted from wastes produced by the wood and wine industries can be an alternative to BPA to produce epoxy resins. The work reported here aims at studying the reactivity of tannins based on a catechin model before identifying tannins as potential substitutes for BPA in the synthesis of biobased epoxy resins. The synthesis of epoxy resins actually requires a first step of functionalization of phenolic hydroxyl groups that cannot be directly investigated on tannins themselves for three main reasons. The first one is that condensed tannins are polymers, the structures and chain lengths of which greatly depend on the plant (even species, organ, and tissue) that produces them, meaning that there is a great structural diversity of tannins in the plant kingdom. Second, due to their polymeric nature, these macromolecules are difficult to analyze and characterize precisely. Therefore, it would be much more challenging to characterize their functionalized products. The third reason is that tannins are not commercial chemicals although tannin extracts can be produced in large quantities but their chemical composition cannot be completely established. They can be prepared in the laboratory with high purity and with a relatively lowproduction scale (typically several hundred milligrams), which limits their use for chemical synthesis. For all these reasons, the goal of this work was to use a representative model for studying tannin reactivity, namely catechin. Indeed, the common feature of tannin structures is the building block of the polymeric chains, which is based on a flavan (2-phenyl chroman)-type structure, consisting of two aromatic rings bearing several hydroxyl groups referred to as A and $\mathrm{B}$ rings which are connected through a central pyran ring, the latter being referred to as C-ring. The most widely spread subunits of tannins in the plant kingdom are (-)-epicatechin and $(+)$-catechin, two flavan-3-ol epimers. The two phenolic rings within the catechin structure differ by their hydroxylation pattern: the two hydroxyl groups of A-ring are in the meta position, while they are in the ortho position on the B-ring. To evaluate the effect of the hydroxylation pattern of aromatic rings toward glycidylation, the reactivity of

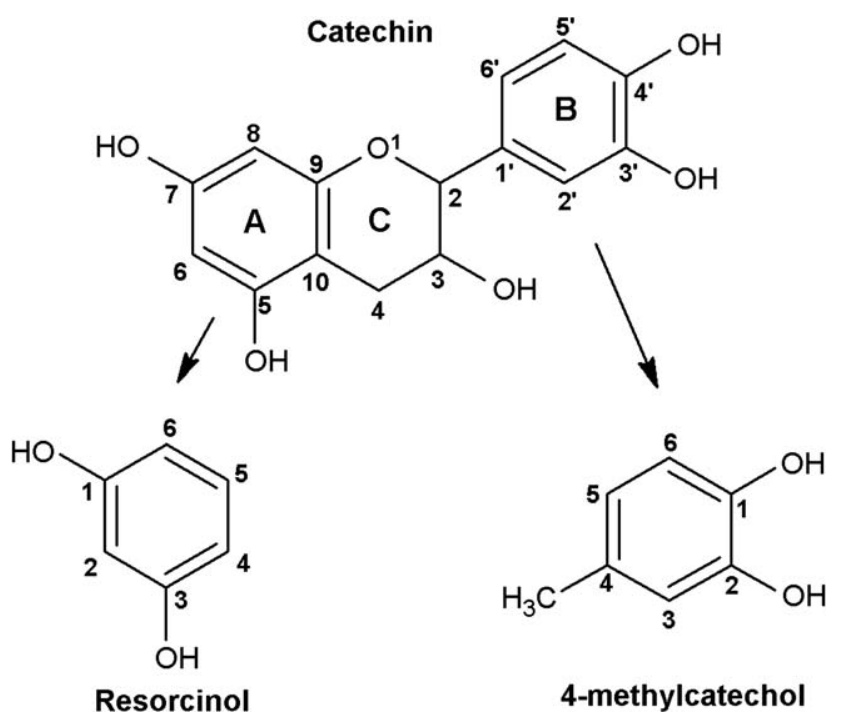

SCHEME 1 Structure of catechin, resorcinol, and 4methylcatechol.

hydroxyl groups was investigated using three different phenolic molecules. Resorcinol and 4-methylcatechol were chosen to mimic the A- and B-rings of catechin, respectively, and the glycidylation was finally applied to catechin itself (Scheme 1). Furthermore, the functionalized catechin was cured, and some properties of the resulting epoxy resin were compared to the standard DGEBA epoxy resin.

\section{EXPERIMENTAL}

\section{Materials}

High performance liquid chromatography (HPLC)-grade ethanol and acetone were purchased from Merck. Catechin $[(+)-$ Catechin hydrate $\geq 98 \%$, epichlorohydrin, sodium hydroxide, resorcinol (SigmaUltra $\geq 98 \%$ ), 4-methylcatechol ( $\geq 98 \%$, HPLC) diglycidyl ether of resorcinol (DGER), potassium hydrogen phthalate, 4-methyl-2-pentanone (ACS Reagent $\geq 98.5 \%$ ) and tetrahydrofuran (THF, puriss.p.a., ACS Reagent $>99.5 \%$ ) were purchased from Sigma-Aldrich.

DGEBA (Epikote 828-Resolution Performance Products) and Epamine PC19 (PO.INT. ER S.r.l.) were supplied by Nanoledge Chemicals. Epamine PC 19 is composed by benzyl alcohol $(<50 \%)$, 1,3-bis(aminomethyl)benzene $(<25 \%)$, 3-aminomethyl-3,5,5-trimethylcyclohexylamine $(<25 \%)$ and BPA-epichlorohydrin polymer $(<20 \%)$.

Glycidylation of resorcinol, 4-methylcatechol, and catechin hydroxyl groups were conducted following the method of St Clair. $^{23}$ The described process leads to the preparation of epoxyalkylaryl ether by the reaction of compounds containing hydroxyl groups directly attached to an aromatic nucleus with a haloepoxyalkane in the presence of a strong alkali.

\section{Glycidylation of Resorcinol}

Resorcinol (2 g, i.e., $0.02 \mathrm{~mol}$, i.e., $0.04 \mathrm{~mol}-\mathrm{OH}$ ) was dissolved in epichlorohydrin (14.8 g, i.e., $0.16 \mathrm{~mol}$ ) and heated under a reflux condenser in a 100-mL three-neck round-bottomed flask at $98{ }^{\circ} \mathrm{C}$ while stirring. An ethanolic solution of 
sodium hydroxide (1.6 g, i.e., $0.04 \mathrm{~mol}, 15-\mathrm{mL}$ ethanol) was added dropwise using a dropping funnel while stirring and heating at $98^{\circ} \mathrm{C}$. After $3 \mathrm{~h}$, the reaction mixture was diluted to $200 \mathrm{~mL}$ with acetone. Salts released as by-products in the reaction medium were filtered out over a $1-\mu \mathrm{m}$ glass-fiber filter. The acetone and nonreacted excess of epichlorohydrin were evaporated using a rotary evaporator at $80{ }^{\circ} \mathrm{C}$ under reduced pressure. The reaction product was then redissolved in acetone $(40 \mathrm{~mL})$, filtered over a $1-\mu \mathrm{m}$ glass-fiber filter, and the filtrate was evaporated under vacuum at $80{ }^{\circ} \mathrm{C}$. This last step was repeated twice. The reaction product was further purified by silica gel chromatography and $3.89 \mathrm{~g}$ of the desired product, namely, the DGER was obtained (molar yield $=87 \%$ ).

\section{NMR Chemical Shifts of Resorcinol Derivatives with Methyloxirane Functions}

${ }^{1} \mathrm{H}$ NMR (500 MHz, DMSO- $\left.d_{6}\right), \delta(\mathrm{ppm}): 2.73$ and $2.87(2 \mathrm{H}$, $\mathrm{H}_{\gamma}$ and $\left.\mathrm{H}_{\gamma^{\prime}}\right), 3.72\left(1 \mathrm{H}, \mathrm{H}_{\beta}\right), 3.84$ and $4.34\left(2 \mathrm{H}, \mathrm{H}_{\alpha}\right.$ and $\left.\mathrm{H}_{\alpha^{\prime}}\right)$, $6.58\left(3 \mathrm{H}, \mathrm{H}_{2}, \mathrm{H}_{4}\right.$, and $\left.\mathrm{H}_{6}\right), 7.21\left(1 \mathrm{H}, \mathrm{H}_{5}\right)$.

${ }^{13} \mathrm{C}$ NMR $\left(125.7 \mathrm{MHz}, \mathrm{DMSO}-d_{6}\right), \delta(\mathrm{ppm}): 45.5\left(\mathrm{CH}_{\gamma}\right.$ and $\left.\mathrm{CH}_{\gamma^{\prime}}\right), 51.4\left(\mathrm{CH}_{\beta}\right), 70.8\left(\mathrm{CH}_{\alpha}\right.$ and $\left.\mathrm{CH}_{\alpha^{\prime}}\right), 103.1\left(\mathrm{C}_{2}\right), 109.0\left(\mathrm{C}_{4}\right.$ and $\left.\mathrm{C}_{6}\right), 131.8\left(\mathrm{C}_{5}\right), 161.2\left(\mathrm{C}_{1}\right.$ and $\left.\mathrm{C}_{3}\right)$.

\section{Glycidylation of 4-Methylcatechol}

4-Methylcatechol (2.48 g, i.e., $0.02 \mathrm{~mol}$, i.e., $0.04 \mathrm{~mol}-\mathrm{OH}$ ) was dissolved in epichlorohydrin (14.8 g, i.e., $0.16 \mathrm{~mol}$ ) and heated under a reflux condenser in a $100 \mathrm{~mL}$ three-neck round-bottomed flask at $98{ }^{\circ} \mathrm{C}$ while stirring. An ethanolic solution of sodium hydroxide $(1.6 \mathrm{~g}$, i.e., $0.04 \mathrm{~mol}, 15 \mathrm{~mL}$ ethanol) was added dropwise using a dropping funnel while stirring and heating at $98{ }^{\circ} \mathrm{C}$. The synthesis proceeded as previously described for resorcinol. $3.86 \mathrm{~g}$ of product was obtained after the glycidylation of methylcatechol. The reaction mixture was further purified by silica gel chromatography and the separation was followed by thin layer chromatography (TLC). Two fractions were collected. The first fraction containing the expected reaction product corresponds to $2.90 \mathrm{~g}$ (yield $=61 \%$ ).

\section{NMR Chemical Shifts of Methylcatechol with Methyloxirane Function}

${ }^{1} \mathrm{H}$ NMR (500 MHz, DMSO- $\left.d_{6}\right), \delta(\mathrm{ppm}): 2.28\left(3 \mathrm{H}, \mathrm{CH}_{3 \mathrm{a}}\right)$, 2.75 and $2.88\left(2 \mathrm{H}, \mathrm{H}_{\gamma \mathrm{a}}\right.$ and $\left.\mathrm{H}_{\gamma^{\prime} \mathrm{a}}\right), 3.38\left(1 \mathrm{H}, \mathrm{H}_{\beta \mathrm{a}}\right), 3.80-3.90$ and 4.26-4.37 $\left(2 \mathrm{H}, \mathrm{H}_{\alpha \mathrm{a}}\right.$, and $\left.\mathrm{H}_{\alpha^{\prime} \mathrm{a}}\right), 6.77\left(1 \mathrm{H}, \mathrm{H}_{5}\right), 6.88(1 \mathrm{H}$, $\left.\mathrm{H}_{3}\right), 6.93\left(1 \mathrm{H}, \mathrm{H}_{6}\right)$.

${ }^{13} \mathrm{C}$ NMR (125.7 MHz, DMSO- $\left.d_{6}\right), \delta$ (ppm): $22.1\left(\mathrm{CH}_{3 \mathrm{a}}\right), 45.4$ $\left(\mathrm{CH}_{\gamma \mathrm{a}}\right.$ and $\left.\mathrm{CH}_{\gamma^{\prime} \mathrm{a}}\right), 51.4\left(\mathrm{CH}_{\beta \mathrm{a}}\right), 71.6\left(\mathrm{CH}_{\alpha \mathrm{a}}\right.$ and $\left.\mathrm{CH}_{\alpha^{\prime} \mathrm{a}}\right), 114.7$ $\left(\mathrm{C}_{3}\right), 116.6\left(\mathrm{C}_{6}\right), 123.1\left(\mathrm{C}_{5}\right), 132.2\left(\mathrm{C}_{4}\right), 147.4\left(\mathrm{C}_{2}\right), 149.5\left(\mathrm{C}_{1}\right)$.

\section{NMR Chemical Shifts of Methylcatechol with Dioxane Function}

${ }^{1} \mathrm{H}$ NMR (500 MHz, DMSO- $\left.d_{6}\right), \delta(\mathrm{ppm}): 2.23\left(3 \mathrm{H}, \mathrm{CH}_{3 \mathrm{~b}}\right)$, 3.63 and $3.67\left(2 \mathrm{H}, \mathrm{H}_{\gamma \mathrm{b}}\right.$, and $\left.\mathrm{H}_{\gamma^{\prime} \mathrm{b}}\right), 4.15\left(1 \mathrm{H}, \mathrm{H}_{\beta \mathrm{b}}\right), 4.04-3.90$ and 4.29-4.36 $\left(2 \mathrm{H}, \mathrm{H}_{\alpha \mathrm{b}}\right.$, and $\left.\mathrm{H}_{\alpha^{\prime} \mathrm{b}}\right), 6.63\left(1 \mathrm{H}, \mathrm{H}_{5}\right), 6.72(1 \mathrm{H}$, $\left.\mathrm{H}_{3}\right), 6.78\left(1 \mathrm{H}, \mathrm{H}_{6}\right)$.

${ }^{13} \mathrm{C}$ NMR (125.7 MHz, DMSO- $\left.d_{6}\right), \delta(\mathrm{ppm}): 21.8\left(\mathrm{CH}_{3 \mathrm{~b}}\right), 61.4$ $\left(\mathrm{CH}_{\gamma \mathrm{b}}\right.$ and $\left.\mathrm{CH}_{\gamma^{\prime} \mathrm{b}}\right), 66.7\left(\mathrm{CH}_{\alpha \mathrm{b}}\right.$ and $\left.\mathrm{CH}_{\alpha^{\prime} \mathrm{b}}\right), 75.2\left(\mathrm{CH}_{\beta \mathrm{b}}\right), 117.0$
$\left(\mathrm{C}_{3}\right), 118.8\left(\mathrm{C}_{6}\right), 123.5\left(\mathrm{C}_{5}\right), 131.9\left(\mathrm{C}_{4}\right), 142.5\left(\mathrm{C}_{2}\right), 144.2$ $\left(\mathrm{C}_{1}\right)$.

\section{Glycidylation of Catechin}

Catechin ( 2 g, i.e., $0.0069 \mathrm{~mol}$, and $0.0345 \mathrm{~mol}-\mathrm{OH}$ ) was dissolved in epichlorohydrin (12.7 g, i.e., $0.137 \mathrm{~mol}$ ) and heated under reflux condenser in a $100-\mathrm{mL}$ three-neck round-bottomed flask at $98{ }^{\circ} \mathrm{C}$ while stirring. An ethanolic solution of sodium hydroxide (1.37 g, i.e., $0.034 \mathrm{~mol}, 12-\mathrm{mL}$ ethanol) was added dropwise using a dropping funnel while stirring and heating of $98{ }^{\circ} \mathrm{C}$. The synthesis proceeded as previously described for resorcinol. The product (1.6 g) was finally obtained after silica gel chromatography (yield $=48 \%$ ).

\section{NMR Chemical Shifts of Catechin Rings}

${ }^{1} \mathrm{H}$ NMR (500 MHz, DMSO- $\left.d_{6}\right), \delta(\mathrm{ppm}): 2.89-3.10\left(2 \mathrm{H}, \mathrm{H}_{4}\right)$, 3.90-4.07 (1H, $\left.\mathrm{H}_{3}\right), 4.64-4.99\left(1 \mathrm{H}, \mathrm{H}_{2}\right), 6.03\left(1 \mathrm{H}, \mathrm{H}_{6}\right), 6.28$ $\left(1 \mathrm{H}, \mathrm{H}_{8}\right), 6.73-7.21\left(3 \mathrm{H}, \mathrm{H}_{2^{\prime}}, \mathrm{H}_{5^{\prime}}, \mathrm{H}_{6^{\prime}}\right)$.

${ }^{13} \mathrm{C}$ NMR (125.7 MHz, DMSO- $\left.d_{6}\right), \delta(\mathrm{ppm}): 28.9-29.7\left(\mathrm{C}_{4}\right)$, $67.3\left(\mathrm{C}_{3}\right), 81.9-83.5\left(\mathrm{C}_{2}\right), 94.3\left(\mathrm{C}_{6}\right), 95.7\left(\mathrm{C}_{8}\right), 103.7\left(\mathrm{C}_{10}\right)$, 114.8-121.9 $\left(\mathrm{C}_{2^{\prime}}, \mathrm{C}_{5^{\prime}}\right.$ and $\left.\mathrm{C}_{6^{\prime}}\right), 133.8-134.2\left(\mathrm{C}_{1^{\prime}}\right), 143.9-$ $151.0\left(\mathrm{C}_{3^{\prime}}, \mathrm{C}_{4^{\prime}}\right), 156.6\left(\mathrm{C}_{9}\right), 158.8\left(\mathrm{C}_{5}\right), 159.5\left(\mathrm{C}_{7}\right)$.

\section{NMR Chemical Shifts of Methyloxirane Function on Catechin}

${ }^{1} \mathrm{H}$ NMR (500 MHz, DMSO- $\left.d_{6}\right), \delta$ (ppm): 2.71-2.93 $\left(2 \mathrm{H}, \mathrm{H}_{\gamma \mathrm{a}}\right.$ and $\left.\mathrm{H}_{\gamma^{\prime} \mathrm{a}}\right), 3.32-3.41\left(1 \mathrm{H}, \mathrm{H}_{\beta \mathrm{a}}\right), 3.75-3.93$ and $4.28-4.42(2 \mathrm{H}$, $\mathrm{H}_{\alpha \mathrm{a}}$, and $\mathrm{H}_{\alpha^{\prime} \mathrm{a}}$ ).

${ }^{13} \mathrm{C}$ NMR (125.7 MHz, DMSO- $\left.d_{6}\right), \delta(\mathrm{ppm}): 45.3\left(\mathrm{CH}_{\gamma \mathrm{a}}\right.$ and $\left.\mathrm{CH}_{\gamma^{\prime} \mathrm{a}}\right), 51.4\left(\mathrm{CH}_{\beta \mathrm{a}}\right), 70.7-71.6\left(\mathrm{CH}_{\alpha \mathrm{a}}\right.$ and $\left.\mathrm{CH}_{\alpha^{\prime} \mathrm{a}}\right)$.

\section{NMR Chemical Shifts of Dioxane Function on Catechin}

${ }^{1} \mathrm{H}$ NMR (500 MHz, DMSO- $\left.d_{6}\right), \delta$ (ppm): 3.68-3.86 $\left(2 \mathrm{H}, \mathrm{H}_{\gamma \mathrm{b}}\right.$, and $\left.\mathrm{H}_{\gamma^{\prime} \mathrm{b}}\right), 3.93-4.07$ and $4.28-4.42\left(2 \mathrm{H}, \mathrm{H}_{\alpha \mathrm{b}}\right.$, and $\left.\mathrm{H}_{\alpha^{\prime} \mathrm{b}}\right), 4.15-$ $4.24\left(1 \mathrm{H}, \mathrm{H}_{\beta \mathrm{b}}\right)$.

${ }^{13} \mathrm{C}$ NMR (125.7 MHz, DMSO-d $\left.d_{6}\right), \delta(\mathrm{ppm}): 61.2\left(\mathrm{CH}_{\gamma \mathrm{b}}\right.$ and $\left.\mathrm{CH}_{\gamma^{\prime} \mathrm{b}}\right), 66.8\left(\mathrm{CH}_{\alpha \mathrm{b}}\right.$ and $\left.\mathrm{CH}_{\alpha^{\prime} \mathrm{b}}\right), 75.2\left(\mathrm{CH}_{\beta \mathrm{b}}\right)$.

Substitution of resorcinol, 4-methylcatechol, and catechin phenolic hydroxyl groups by methyloxirane functions is described in a recent patent. ${ }^{24}$

\section{FTIR Spectroscopy}

Infrared spectral acquisition was performed with an Avatar 360 spectrophotometer equipped with Omnic software (Nicolet, Madison). The samples were placed in contact with the ATR single reflection cell consisting of germanium crystal. A micrometric screw applying constant pressure ensured good contact between the sample and the crystal. The background spectrum was acquired in air. Each spectrum is the average of 22 scans from 600 to $4000 \mathrm{~cm}^{-1}$ at an ambient temperature in the range of $20^{\circ} \mathrm{C}$.

\section{NMR Spectroscopy}

NMR spectra were acquired on a Varian Unity Inova 500 MHz spectrometer (Varian Palo Alto, CA) at $298 \mathrm{~K}$ using a 3$\mathrm{mm}$ indirect detection probe equipped with a z-gradient coil. Samples $(\sim 5 \mathrm{mg})$ were dissolved in deuterated dimethyl sulfoxide (DMSO- $d_{6}$ ) in the presence of sodium 3-trimethylsilylpropionate- $d_{4}$ (TMSP) as an internal reference. All 
spectra were referenced on the ${ }^{1} \mathrm{H}$ and ${ }^{13} \mathrm{C}$ signals of TMSP at 0 ppm. One-dimensional (1D) ${ }^{1} \mathrm{H}$, two-dimensional (2D) homonuclear ${ }^{1} \mathrm{H}$ (COSY, ROESY), and 2D heteronuclear ${ }^{1} \mathrm{H}-{ }^{13} \mathrm{C}$ (HSQC, HMBC) spectra were performed.

Proton 2D diffusion-ordered experiments (2D DOSY) were performed using the Varian pulse sequence DgcsteSL. Diffusion delay time and gradient pulse width were 200 and 4 $\mathrm{ms}$, respectively. The gradient strength (g) was incremented in 16 steps with equal $g^{2}$ spacing from 0.3 to $32 \mathrm{G} \mathrm{cm}^{-1}$ that allowed the NMR signals of interest to be attenuated at $\sim 5 \%$ of the original intensity. The $1 \mathrm{D}$ spectra were processed by multiplication with Gaussian curves followed by Fourier transformation. Additionally, the spectra were then phase and baseline corrected. The DOSY processing program implemented in the VNMR software was used to calculate the diffusion coefficient and to create 2D spectra with NMR chemical shifts along $1 \mathrm{D}$ and the calculated diffusion coefficient along the other.

\section{Determination of the Epoxy Index}

The epoxy index (epoxide equivalent/kg of resin) was determined by chemical assay using a previously described method. ${ }^{25}$ When epoxy products are present in the reaction media, addition of $\mathrm{HBr}$ leads to the opening of epoxy functions. When all the epoxy functions are opened by $\mathrm{HBr}$, further addition of $\mathrm{HBr}$ results in the blue-green end of crystal violet indicator.

\section{Formulation of the Cured Epoxy Resins}

The cured samples of 25DGEBA/75GEC and 50DGEBA/ 50GEC were the abbreviations of the reaction systems containing DGEBA/glycidyl ether of catechin (GEC) with 25:75 and 50:50 weight ratio, respectively. All the reaction systems were prepared in a 1:1 molar ratio of epoxy group to active $\mathrm{H}$ of amine in the curing agent to obtain the optimal crosslinking architecture of cured epoxy materials. Epoxy samples were cured at $60{ }^{\circ} \mathrm{C}$ for $24 \mathrm{~h}$.

\section{Thermal Analysis}

Thermogravimetric analyses (TGA) of various cured resins composed of glycidyl ether products were performed on a Perkin Elmer TGA6 instrument. The initial weight of each sample tested was approximately $5 \mathrm{mg}$. Each sample was heated from 20 to $900{ }^{\circ} \mathrm{C}$ at a heating rate of $10{ }^{\circ} \mathrm{C} \mathrm{min}-1$ under nitrogen atmosphere. Degradation temperatures at $5 \%$ $\left(T_{\mathrm{d} 5}\right)$ and $30 \%\left(T_{\mathrm{d} 30}\right)$, weight loss, and the char yield at 800 ${ }^{\circ} \mathrm{C}\left(\mathrm{Char}_{800}\right)$ were then recorded for various cured resins.

\section{Dynamic Mechanical Analysis}

The temperature dependencies of the viscoelastic properties (storage modulus: $G^{\prime}$ and mechanical loss tangent: $\tan \delta$ ) of the cured resins were evaluated by dynamical analyses (DMA) in the bending mode using a frequency of $5 \mathrm{~Hz}$. The instrument used was a DMTA Metravib VA815-RDS. DMA specimens were in the form of rectangular bars of nominal size $2 \times 10 \times 30 \mathrm{~mm}^{3}$. The samples were tested over a temperature range from ambient temperature to $120{ }^{\circ} \mathrm{C}$ with a heating rate of $3{ }^{\circ} \mathrm{C} \mathrm{min}^{-1}$. The glass-transition temperature $\left(T_{\mathrm{g}}\right)$ was assigned as the temperature where the loss factor

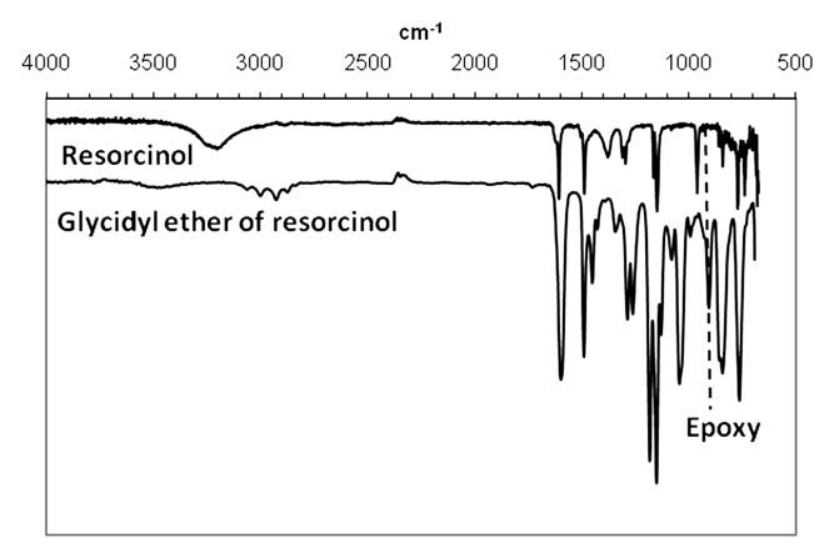

FIGURE 1 IR transmission spectra of resorcinol and glycidyl ether of resorcinol.

was a maximum. Two specimens of each composition were tested.

\section{Swelling Measurements}

Swelling measurements of the networks were carried out using THF as the diffusing agent. The swelling percentage was calculated from the differences in weight between dried and swollen networks. Bars samples $\left(3 \mathrm{~mm}^{3}\right)$ of the cured epoxy resins were cut, weighed, and immersed in THF for 24 h. The samples were then swollen with solvent quickly blotted between sheets of paper and finally weighted. The swelling percentage was calculated as follows:

$$
\text { Swelling }(\%)=\left(W_{\mathrm{s}}-W_{\mathrm{d}}\right) / W_{\mathrm{d}} \times 100
$$

where $W_{\mathrm{s}}$ and $W_{\mathrm{d}}$ are the weights of the swollen bar and the dried bar, respectively.

The swollen bars were put in an oven at $60{ }^{\circ} \mathrm{C}$ for $24 \mathrm{~h}$ to dry them. Then, the bars were weighed $\left(W_{\mathrm{do}}\right)$ :

$$
\text { Soluble part }(\%)=100-\left[\left(W_{\mathrm{do}} / W_{\mathrm{d}}\right) \times 100\right]
$$

\section{RESULTS}

Resorcinol, 4-methylcatechol, and catechin were reacted with epichlorohydrin in alkaline medium to synthesize the corresponding glycidyl ether derivatives afterward referred to as GER, GEMC, and GEC, respectively. For each phenolic compound, the reaction products were characterized by both FTIR and NMR spectroscopy.

\section{FTIR Analysis}

The product obtained from the glycidylation of resorcinol was analyzed by FTIR spectroscopy and compared to resorcinol (Fig. 1). Functionalization of the hydroxyl groups in resorcinol was revealed by the disappearance of the broad band in the region of $3500-3000 \mathrm{~cm}^{-1}$ associated with the stretching vibration of the inter- and intra-molecular hydrogen bonded phenolic $-\mathrm{OH}$. It was also revealed by the appearance of a band at $1100 \mathrm{~cm}^{-1}$ attributed to the vibration of an aliphatic ether. Moreover, new bands emerged at $2880,2930,3010$, and $3080 \mathrm{~cm}^{-1}$, which were assigned to 


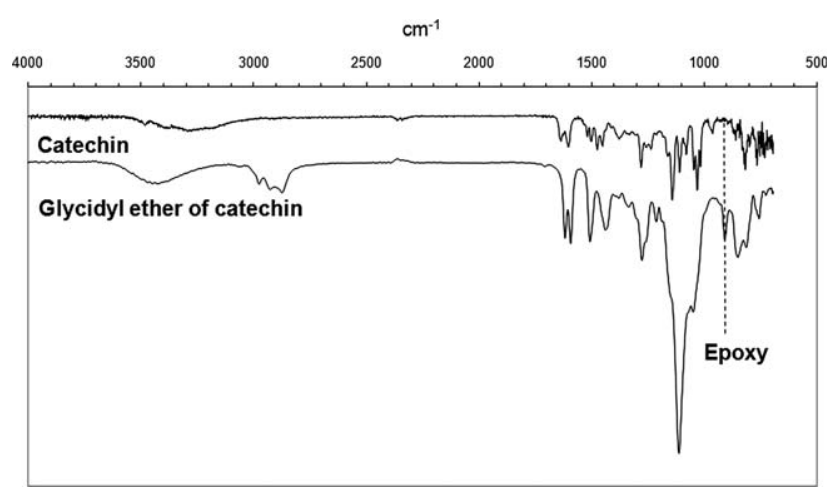

FIGURE 2 IR transmission spectra of catechin and glycidyl ether of catechin.

the vibration of methylene groups of the methyloxirane functions. Additionally, the band appearing at $910 \mathrm{~cm}^{-1}$ (shown as the dotted line in Fig. 1) was attributed to the vibration of epoxy groups. FTIR analyses, thus, showed the presence of methyloxirane groups after reaction.

For the glycidylation product of methylcatechol, the specific bands related to methyloxirane groups were also present on the IR spectrum confirming that some substitution occurred in the course of the reaction (Figure not shown). Unlike resorcinol product, the presence of hydroxyl groups in the reaction products of methylcatechol was suggested by the shift to slightly higher values of the broad band in the region of $3500-3000 \mathrm{~cm}^{-1}$ corresponding to the inter- and intra-molecular hydrogen bonded phenolic $-\mathrm{OH}$ stretching vibration in methylcatechol.

The IR spectrum of GEC is well resolved and can be compared to the IR spectrum of its starting material, namely catechin (Fig. 2). The broad band in the region of 3500-3000 $\mathrm{cm}^{-1}$ shifted to slightly higher values as was already noted for methylcatechol product, indicating the presence of hydroxyl groups in glycidyl ether derivatives of catechin as well. New bands emerged at $1100 \mathrm{~cm}^{-1}$, attributed to the vibration of aliphatic ether, between 2900 and $3000 \mathrm{~cm}^{-1}$, which corresponds to the vibration of methyl groups of the methyloxirane functions and at $910 \mathrm{~cm}^{-1}$, which corresponds to the vibration of epoxy groups indicating the formation of methyloxirane functions. Again, FTIR analyses confirmed the presence of methyloxirane functions on catechin.

NMR Analysis and Chemical Assay

The ${ }^{1} \mathrm{H}$ 2D DOSY spectrum of glycidyl ether product of resorcinol (GER) (Figure not shown) showed that the most intense signals in the spectrum appeared with the same diffusion coefficient value, indicating the presence of one major reaction product. The typical ${ }^{1} \mathrm{H}$ resonances and the ${ }^{1} \mathrm{H}_{-}{ }^{13} \mathrm{C}$ long range correlations allowed the major product to be identified as the glycidyl ether of resorcinol. The heteronuclear multiple bond coherence (HMBC) spectrum also showed that $O$-alkylation occurred at both the $\mathrm{C} 1$ and $\mathrm{C} 3$ ring positions, whereas no $C$-alkylation could be detected. Signals arising from minor species (likely by products) were also observed on the DOSY spectrum.
The average number of methyloxirane functions per resorcinol ring, calculated from the ratio of ${ }^{1} \mathrm{H}$ signal integrations of the $\mathrm{H}_{\alpha}$ aliphatic protons of methyloxirane to the $\mathrm{H}_{5}$ aromatic protons of resorcinol rings are indicated in Figure 3, and was about 1.8. The same value was found for commercial DGER from its ${ }^{1} \mathrm{H}$ 1D spectrum.

The Epoxy index of synthesized GER determined by chemical assay is 7.7, which represents 1.5 methyloxirane functions per molecule. For comparison, the epoxy index of commercial DGER is 8.0, which lead to 1.6 methyloxirane functions per molecule.

This set of analytical data clearly showed the formation of DGER as the main reaction product.

The ${ }^{1} \mathrm{H}$ 2D DOSY spectrum obtained after the glycidylation of 4-methylcatechol (Figure not shown) showed the presence of two major products that differ by a slight modification in both the diffusion coefficient values and ${ }^{1} \mathrm{H}$ chemical shifts. This indicated a structural similarity of these two compounds.

The ${ }^{1} \mathrm{H}^{-13} \mathrm{C}$ HMBC spectrum was used to characterize these two main products. We, thus, found that these compounds consisted of 4-methylcatechol derivatives, alkylated on the hydroxyl groups at the $\mathrm{C} 1$ and/or $\mathrm{C} 2$ positions. Moreover, the NMR spectra allowed two kinds of substitution patterns to be distinguished: the expected methyloxirane group and a benzodioxane-type moiety, namely the 6-methyl-2-hydroxymethyl-1,4-benzodioxane (Fig. 4) involving the two phenolic hydroxyl groups of methylcatechol. This benzodioxane-type substituent is composed of as many protons and carbons as the methyloxirane group but some of its chemical shifts and proton coupling constants are different, especially the $\mathrm{H}_{\beta \mathrm{b}}$ and $\mathrm{H}_{\gamma \mathrm{b}} \mathrm{H}_{\gamma^{\prime} \mathrm{b}}$, which emerged to as higher chemical shifts. The NMR chemical shifts for this kind of structure reported in the literature or calculated using ChemDraw software are consistent with the values found. ${ }^{26,27}$ Moreover, the $C$-alkylation of 4-methylcatechol has not been detected from neither ${ }^{1} \mathrm{H}$ spectrum nor HMBC spectrum.

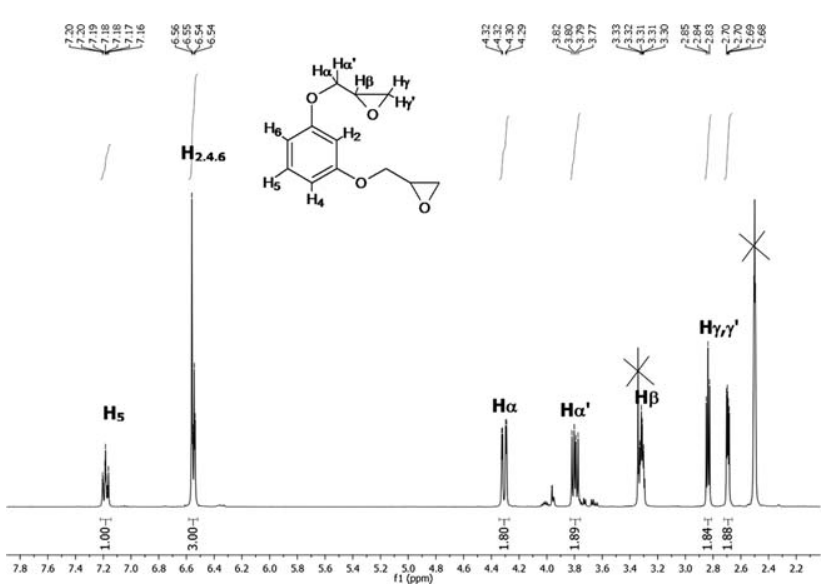

FIGURE $3{ }^{1} \mathrm{H}$ NMR spectrum of glycidyl ether of resorcinol. 


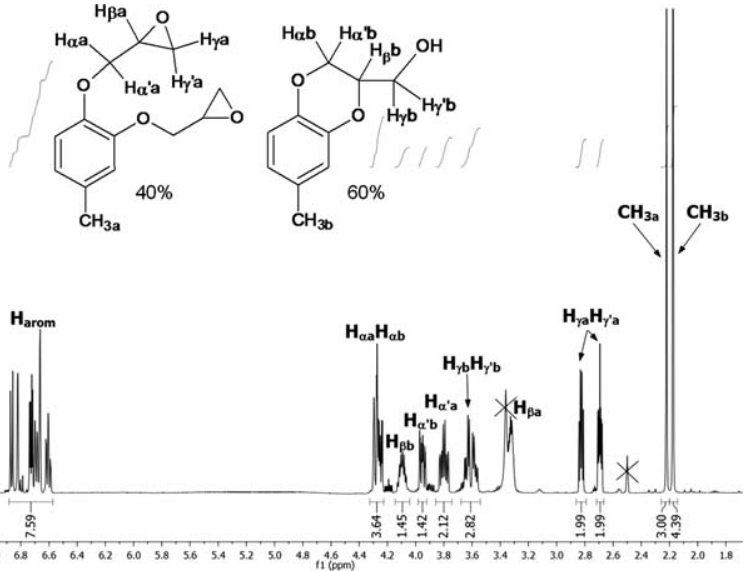

FIGURE $4{ }^{1} \mathrm{H}$ NMR spectrum of glycidyl ether of 4-methylcatechol. The structures of the two major products are shown above. The protons of the different substituents and their respective chemical shifts have been labeled as follows: the Greek character referred to as the proton location within the substituent whereas the second character referred to as the type of substituent ( $a$ for methyloxirane-type and $b$ for benzodioxane-type).

NMR chemical shifts of the methyl protons assigned to 4methylcatechol derivatives with methyloxirane functions (atype) were slightly higher than the chemical shifts of methyl protons assigned to 4-methylcatechol derivatives with benzodioxane-type substitution (b-type) (Fig. 4). Thus, the percentage of 4-methylcatechol derivatives with benzodioxane-type function, calculated from the $\mathrm{CH}_{3 \mathrm{a}}$ and $\mathrm{CH}_{3 \mathrm{~b}}$ proton signal integrations, was $60 \%$. Moreover, using $\mathrm{H}_{\gamma \mathrm{a}}$ (or $\mathrm{H}_{\gamma^{\prime} \mathrm{a}}$ ) and $\mathrm{CH}_{3 a}$ proton signal integrations, it was found that the number of methyloxirane groups (a-type) per 4-methylcatechol ring was 2 . Consequently, the glycidylation products of meth- ylcatechol are two 4-methylcatechol derivatives, obtained in the following proportions: $60 \%$ of benzodioxane-type 4methylcatechol derivative and $40 \%$ of the diglycidyl ether of 4-methylcatechol. This product distribution should lead to 0.8 epoxy function per 4-methylcatechol molecule. A value of $\sim 0.9$ methyloxirane function per 4-methylcatechol molecule was found by chemical assay in accordance with the NMR characterization.

DOSY spectrum of glycidylation products of catechin (GEC) (Fig. 5) displayed most of the diffusion coefficient values of catechin derivatives in a narrow width distribution indicating that the reaction products have comparable molecular weights. Moreover, we found that these diffusion coefficient values were in the same order of magnitude with that of pure catechin in the same solvent (result not shown), meaning that the main reaction products were monomeric catechin unit derivatives. The HMBC spectrum showed that alkylation occurred on all hydroxyl positions of the phenolic rings, that is, at $\mathrm{C} 5$ and $\mathrm{C} 7$ of $\mathrm{A}$ ring and at $\mathrm{C} 3^{\prime}$ and $\mathrm{C} 4^{\prime}$ of $\mathrm{B}$ ring. However, neither $O$-alkylation on the hydroxyl position at $\mathrm{C} 3$ of the heterocyclic $\mathrm{C}$ ring nor $C$-alkylation at the carbons adjacent to hydroxyl groups of the phenolic $\mathrm{A}$ and $\mathrm{B}$ rings (see Scheme 1 for catechin labeling) were detected. Besides, the chemical shifts of benzodioxane-type substituent different from those of methyloxirane group that was first detected in the methylcatechol product spectrum, were also present in the ${ }^{1} \mathrm{H}$ 1D NMR spectrum of GEC.

The average number of substituents per catechin molecule, determined from the ${ }^{1} \mathrm{H}$ 1D NMR spectrum using signal integration of all $\mathrm{H}_{\alpha}\left(\mathrm{H}_{\alpha \mathrm{a}}\right.$ and $\left.\mathrm{H}_{\alpha \mathrm{b}}\right)$ and aromatic protons of $\mathrm{B}$ ring $\left(\mathrm{H}_{2^{\prime}}, \mathrm{H}_{5^{\prime}}\right.$, and $\mathrm{H}_{6^{\prime}}$ ), (Fig. 5) was approximately 3.4. However, based on the ratio of ${ }^{1} \mathrm{H}$ signal integrations of methyloxirane $\mathrm{H}_{\gamma}$ protons $\left(\mathrm{H}_{\gamma \mathrm{a}}\right.$ and $\left.\mathrm{H}_{\gamma^{\prime} \mathrm{a}}\right)$ to $\mathrm{B}$ ring aromatic protons, an average number of methyloxirane groups per catechin molecule was found approximately at 2.9 . These calculations

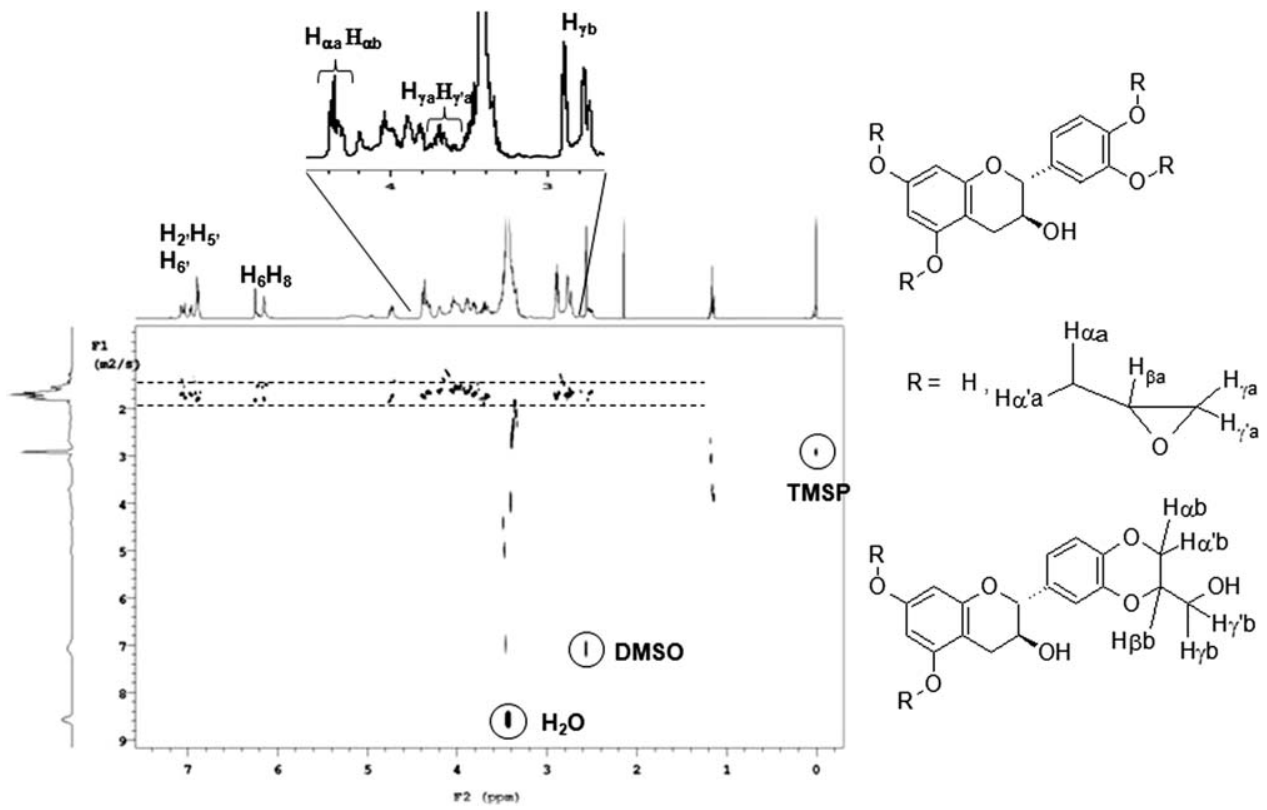

FIGURE $5{ }^{1} \mathrm{H} \quad$ 2D DOSY NMR spectrum of glycidyl ether of catechin. The structures of the two major products are shown above. The protons of the different substituents and their respective chemical shifts have been labeled as those of methylcatechol products. 


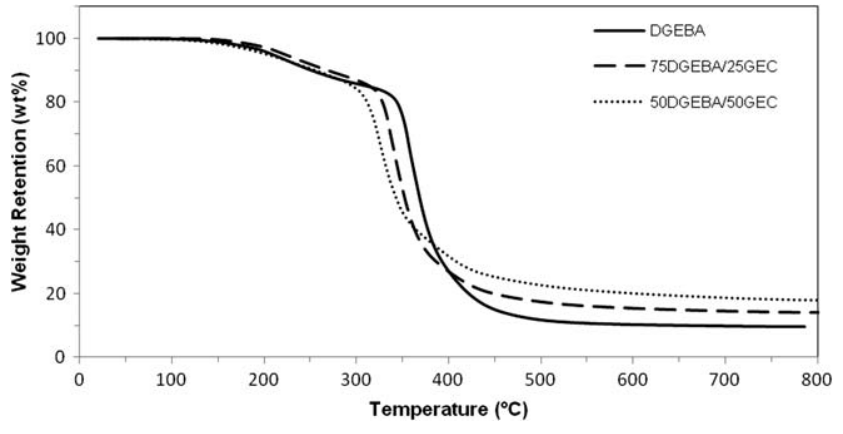

FIGURE 6 Thermogravimetric analysis traces of DGEBA, 75DGEBA/25GEC, and 50DGEBA/50GEC cured epoxy resins.

led to a 52:48 molar ratio of benzodioxane-(a-type) to methyloxirane-(b-type) catechin derivatives. The benzodioxanetype catechin derivative contains two methyloxirane functions located on the A-ring per catechin molecule, whereas the methyloxirane-type catechin derivative contains four methyloxirane functions per catechin molecule. Given the relative proportions found for a- and b-type catechin derivatives, this means that the glycidylation of catechin leads, in average, to $73 \%$ of methyloxirane functions and $27 \%$ of benzodioxane-type functions per catechin molecule. Using proton signal integration of $\mathrm{H}_{\gamma \mathrm{b}}$ as indicated in Figure 5, it was actually found approximately $\sim 20 \%$ of benzodioxane-type substituent against all catechin substituents.

\section{Epoxy Resins Formulation}

GEC was tested in an epoxy resin formulation and compared to a pure commercial DGEBA. Resins were formulated at ambient temperature and cured at $60{ }^{\circ} \mathrm{C}$ for $24 \mathrm{~h}$. The curing agent was Epamine PC 19, a commercial amine hardener for epoxy systems based on a cycloaliphatic amine, providing low viscosity and fast curing even at low temperatures. Composition of Epamine PC 19 is given in the Experimental section.

As GEC was a solid compound at ambient temperature, it was mixed with DGEBA to lower the viscosity of the epoxy resin and to formulate at ambient temperature. In this case, DGEBA was actually used as reactive diluent. Thermal stability, swelling properties, and dynamic mechanical properties of the resins were tested and compared to the commercial DGEBA. The DGEBA/GEC mixtures used were done at two different weight ratios 75/25 and 50/50.

\section{Thermal Stability and Dynamic Mechanical Properties of Various Cured Epoxy Resins}

Figure 6 displays the plots of TGA obtained from DGEBA and DGEBA/GEC cured epoxy resins. The characteristic values calculated from these curves are given in Table 1 . The statistic heat-resistant index temperature $\left(T_{\mathrm{S}}\right)$ is characteristic of the thermal stability of the cured resins. This value is determined from the temperatures at $5 \%$ weight loss $\left(T_{\mathrm{d} 5}\right)$ and $30 \%$ weight loss $\left(T_{\mathrm{d} 30}\right)$ of the sample obtained by thermogravimetric analysis (TGA). The statistic heat resistant index temperature $\left(T_{\mathrm{s}}\right)$ is calculated by eq $1 .^{28-30}$

$$
T_{\mathrm{s}}=0.49\left[T_{\mathrm{ds}}+0.6 \times\left(T_{\mathrm{d} 30}-T_{\mathrm{d} 5}\right)\right]
$$

The values of statistic heat-resistant index $\left(T_{\mathrm{s}}\right)$ of the resins containing synthesized GEC were lower compared to commercial DGEBA. The addition of GEC into DGEBA slightly lowered the thermal stability of the cured resins.

Residual materials of resins at $800{ }^{\circ} \mathrm{C}$ are presented in Table 1. Char 800 values were higher for the resins containing GEC compared to commercial DGEBA and the presence of GEC in DGEBA resins induced a significant increase of the Char 800 values. These results indicated that the GEC had a positive effect in that they diminished the resin decomposition.

To evaluate the effect of the GEC content on glass-transition temperature and crosslinking density of cured epoxy resins, the storage modulus $\left(G^{\prime}\right)$ and loss factor $(\tan \delta)$ were calculated by using DMA. Figure 7 shows the temperature dependence of the storage modulus $G^{\prime}$ of cured DGEBA/GEC specimens. The storage modulus $G^{\prime}$ of the cured DGEBA/GEC specimens slightly decreased when increasing GEC content. The glass-transition temperature $\left(T_{\mathrm{g}}\right)$ was assigned as the temperature where the loss factor was at a maximum. The crosslinking density $(\rho)$ of cured specimens was calculated from the equilibrium storage modulus $\left(G^{\prime}\right)$ in the rubber region over the $\alpha$-relaxation temperature according to rubber elasticity theory given by eq $2 .{ }^{31}$

$$
\rho=G^{\prime} /(\phi \mathrm{RT})
$$

$T_{\mathrm{g}}$ is the $\alpha$-relaxation glass temperature, $G^{\prime}$ the storage modulus at $T_{\mathrm{g}}+30{ }^{\circ} \mathrm{C}, \phi$ the front factor (approximated to 1 in the Flory theory), ${ }^{32} R$ the gas constant, and $T$ the absolute temperature at $T_{\mathrm{g}}+30{ }^{\circ} \mathrm{C}$.

The obtained $T_{\mathrm{g}}$, storage moduli $\left(G^{\prime}\right)$, and crosslinking densities $(\rho)$ of the specimens are summarized in Table 2. $T_{\mathrm{g}}$ is

\begin{tabular}{|c|c|c|c|c|c|c|}
\hline Samples & $T_{\mathrm{d} 5}\left({ }^{\circ} \mathrm{C}\right)^{\mathrm{a}}$ & $T_{\mathrm{d} 30}\left({ }^{\circ} \mathrm{C}\right)^{\mathrm{b}}$ & $T_{\mathrm{s}}^{\mathrm{c}}$ & Char $_{800}(\%)^{d}$ & Swelling (\%) & Soluble Part (\%) \\
\hline DGEBA & 209 & 355 & 145 & 10 & 17 & 1 \\
\hline 75DGEBA/25GEC & 221 & 337 & 142 & 14 & 4 & 1 \\
\hline 50DGEBA/50GEC & 202 & 323 & 135 & 18 & 1 & 1 \\
\hline
\end{tabular}

TABLE 1 Parameters Related to Thermal Stability, Swelling Percentage, and Soluble Part of Various Cured Epoxy Resins 


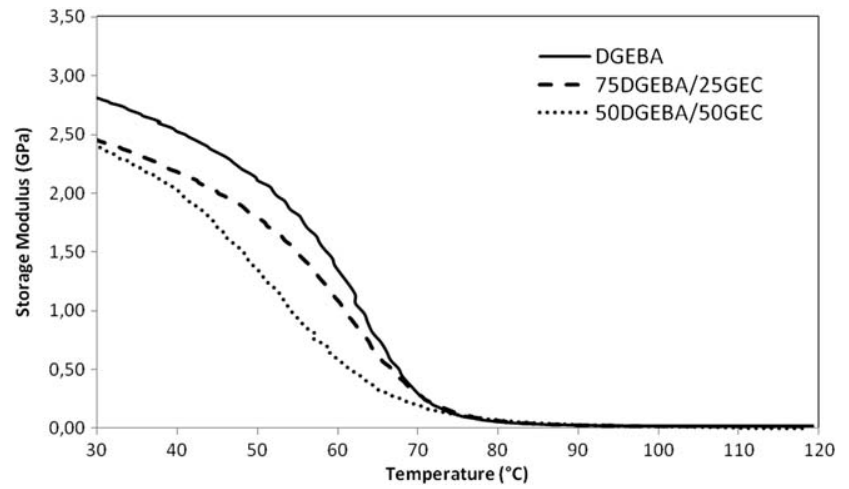

FIGURE 7 Storage modulus $\left(G^{\prime}\right)$ of the DGEBA and DGEBA/ GEC-cured epoxy resins as a function of temperature.

a parameter, which can be used to show the differences in crosslinking density or degree of cure. The $T_{\mathrm{g}}$ of the cured DGEBA epoxy resins polyblended with 25 and $50 \%$ of GEC were the same as the $T_{\mathrm{g}}$ of the cured pure commercial DGEBA. The addition of GEC in DGEBA epoxy resins does not modify the $T_{\mathrm{g}}$, indicating that the presence of GEC does not significantly modify the internal structure of the polymer network. However, crosslinking densities calculated by eq 2 were lowered by increasing the amount of GEC in the epoxy resins.

\section{Swelling Properties}

The swelling test leads to two characteristic properties: the swelling provides information about the crosslinking density of resins and the soluble part gives quantitative information about molecules, which are not implicated in the cured resin network.

The higher the crosslinking density, the shorter the distance between crosslinking nodes and, thus, the lesser solvent (THF) the material absorbs. Results obtained for the various cured epoxy resins are displayed in Table 1.

The swelling proportions and soluble parts were both in agreement with the structural characterization of the catechin glycidyl ether products. Samples containing GEC exhibited lower swelling percentages than DGEBA, and the swelling percentage decreases with increased GEC contents. This finding indicates an increase of the crosslinking density.

TABLE 2 Dynamic Mechanical Analysis of the DGEBA/GECCured Epoxy Resins

\begin{tabular}{|c|c|c|c|c|}
\hline \multirow[b]{2}{*}{ Samples } & \multirow[b]{2}{*}{$\begin{array}{l}T_{\mathrm{g}} \\
\left({ }^{\circ} \mathrm{C}\right)\end{array}$} & \multicolumn{2}{|c|}{$\begin{array}{l}\text { Storage Modulus } \\
\qquad(\mathrm{GPa})\end{array}$} & \multirow[b]{2}{*}{$\left.\rho 10^{-3} \mathrm{~mol} \mathrm{~cm}^{-3}\right)$} \\
\hline & & $\begin{array}{l}\text { Glassy } \\
\text { Region }^{a}\end{array}$ & $\begin{array}{l}\text { Rubbery } \\
\text { Region }^{\text {b }}\end{array}$ & \\
\hline DGEBA & 209 & 2.81 & 0.019 & 6.06 \\
\hline 75DGEBA/25GEC & 221 & 2.46 & 0.016 & 5.12 \\
\hline 50DGEBA/50GEC & 202 & 2.40 & 0.014 & 4.48 \\
\hline
\end{tabular}

Moreover, the replacement of DGEBA by 25 or $50 \%$ of GEC did not modify the soluble part of the resin, which stayed equal to $1 \%$. These results indicate that all components of the GEC product do participate to the network.

\section{DISCUSSION}

Two models compounds were picked for this study. Resorcinol was chosen as a model of the catechin A ring, because it bears two free hydroxyl groups in the same meta positions as catechin, and 4-methylcatechol was chosen as a model of the catechin B ring, because it bears two $\mathrm{OH}$ groups in the same ortho positions as catechin (see Scheme 1). Even though epicatechin, a stereoisomer of catechin, is the most common monomeric unit of tannins in the plant kingdom, catechin was preferred as a model molecule due to price consideration. This choice is justified by the fact that the reactivity of these two stereoisomers toward glycidylation should be similar, because they have the same hydroxyl phenolic patterns.

The structural characterization of the products obtained by the glycidylation of the model molecules clearly showed a difference in reactivity of the two phenolic $\mathrm{OH}$ groups according to their positions on the aromatic ring.

Thus, both FTIR and NMR analyses indicated a complete glycidylation of the phenolic $\mathrm{OH}$ in meta positions of the resorcinol ring after reaction with epichlorohydrin. A low proportion $(\sim 10 \%)$ of by products could be estimated from the DOSY NMR experiment. Some of these by-products with diffusion coefficient close to that of GER may result from polyaddition of epichlorohydrin [Fig. 8(a)], formation of $\beta$-chlorohydrin [Fig. 8(b)], or $\alpha$-glycol [Fig. 8(c)]. Other by-products detected as traces in the DOSY spectrum and having lower diffusion coefficient value (i.e., higher molecular weight) may correspond to reaction by-products resulting from homopolymerization of the resin [Fig. 8(d)]. All of these by-products have also been observed in the case of BPA glycidylation. ${ }^{33,34}$

The slight difference in the average number of methyloxirane functions per resorcinol ring given by the chemical assay<smiles>OCC(O)COC(CO)COc1cccc(OCC2CO2)c1</smiles>

a<smiles>OCC(O)COc1cccc(OCC2CO2)c1</smiles>

c

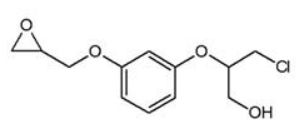

b
FIGURE 8 Possible by-products resulting from polyaddition of epichlorohydrin (a), formation of $\beta$-chlorohydrin (b), formation of $\alpha$-glycol (c), or homopolymerization of the resin (d) obtained during glycidylation of resorcinol. 
(1.5) and calculated from NMR data (1.8) may be explained by the presence of residual salts that were not removed in the work up of the reaction: these residual salts are taken into account in weighting the sample for chemical assay of methyloxirane functions whereas, in NMR, only the protonated species are used for the ratio calculation.

The preferential formation of DGER as the main reaction product showed that the meta-substitution pattern of resorcinol hydroxyl groups is particularly suitable for the double $O$-alkylation.

Conversely, the ortho positions of the two phenolic $\mathrm{OH}$ groups on the benzene ring of 4-methylcatechol leads to two competitive substitution pathways once the first glycidylation occurred: either the second phenolate anion reacts with a second molecule of epichlorohydrin to finally give the expected diglycidylether of 4-methylcatechol; or the oxirane ring introduced in the first substitution step undergoes an intramolecular nucleophilic attack from the second phenolate anion to yield the benzodioxane-type derivative. The two products arising from these competitive reactions could not be isolated separately by silica gel chromatography, as they were coeluted. Nevertheless, their relative proportions $(60: 40$, benzodioxanetype/methyloxirane-type) in the crude material recovered after the chromatography purification could be achieved by NMR analyses, in agreement with the chemical assay.

Thus, it was found that the ortho-substitution pattern of the hydroxyl groups on the benzene ring of 4-methylcatechol is prone to a benzodioxane-type substitution in addition to the double $O$-alkylation.

With respect to resorcinol and 4-methylcatechol, flavan-3-ols such as catechin exhibit competitive deprotonation on both $\mathrm{B}$ and A rings leading to a mixture of different monophenolates. The first dissociation constants of all four phenolic $\mathrm{OH}$ groups are close, and the different hydroxyl groups can be ordered according to their acidity in the sequence: $\mathrm{p} K_{3^{\prime}-O H}=$ 9.02, $\mathrm{p} K_{4^{\prime}-\mathrm{OH}}=9.12, \mathrm{p} K_{5-\mathrm{OH}}=9.43, \mathrm{p} K_{7-\mathrm{OH}}=9.58 .^{35,36} \mathrm{As}$ $\mathrm{NaOH}$ was in large excess for catechin glycidylation, hydroxyl groups on the A and B rings are successively under phenolate form, which should result in a large majority of catechin with four methyloxirane functions.

The preferential formation of the catechin derivatives with three methyloxirane functions on average was, thus, consistent with the glycidylation products obtained with the phenolic ring models: two methyloxirane functions on the A ring and about one methyloxirane function on average on the $\mathrm{B}$ ring. In particular, the benzodioxane-type structure observed on glycidylation of 4-methylcatechol was also detected in catechin products. Thus, the benzodioxane-type catechin derivative actually contains two methyloxirane functions on the A ring and the benzodioxane-type substituent on the B ring, whereas the methyloxirane-type catechin derivative contains four methyloxirane functions on A and B rings. Here again, the molar proportion of the catechin derivative bearing the benzodioxane-type moiety is slightly higher than the proportion of the catechin derivative bearing solely methyloxirane functions. The preferred formation of the benzodioxane derivative may be explained by the higher kinetics of the intramolecular cyclization compared to the intermolecular process yielding the dimethyloxirane derivative.

The benzodioxane function, representing roughly $20 \%$ of GEC substituents, was not really intended because it does not participate to the polymer network when GEC was formulated with Epamine PC19. However, no decrease in the glass-transition temperature was observed when incorporating GEC into the DGEBA resin up to $50 \%$. Indeed, the catechin derivatives substituted by a benzodioxane-type function on the $\mathrm{B}$ ring have also two methyloxirane functions on the A ring and thus participate to the network.

Epoxy resins formulated with GEC have a higher crosslinking density (result found by the swelling tests) in accordance with the number of methyloxirane functions per aromatic molecule, which was found to be close to 3 for catechin, whereas it was $\sim 2$ for DGEBA. In addition, the presence of two methyloxirane functions on the same aromatic ring (A ring) in GEC restricts the distance between nodes in the polymer network and thus increases the crosslinking density. On the contrary, crosslinking densities calculated from eq 2 based on rubber elasticity theory using DMA analysis showed lower crosslinking densities for epoxy resins formulated with GEC. As discussed above, these results are quite surprising as both the internal structure of catechin and the higher functionality of GEC compared to DGEBA was supposed to lead to an increase in the rigidity and the crosslinking density of the network and a restriction of the motions within the molecular chains. The theoretical value of 1 taken for the front factor can be an explanation of these results, because the front factor is strongly dependent on the functionality of the network junctions. The conformation of the network in DGEBA epoxy resin surely differs from the conformation of the network when GEC was added, and, consequently, the value of the front factor should be different. ${ }^{37}$

\section{CONCLUSIONS}

The first part of this study led to conclude that differences in the reactivity of phenolic $\mathrm{OH}$ groups do exist according to their meta and ortho positions on the benzene ring of resorcinol and 4-methylcatechol, respectively, chosen to represent the $A$ and $B$ rings of the flavonoid repetitive unit in tannins. Indeed, under the same reaction conditions, substitution of the two hydroxyl groups in the meta position by methyloxirane functions is observed in resorcinol whereas only one hydroxyl group on average is substituted in 4-methylcatechol, where the hydroxyl groups are both in ortho positions. The reactivity of the two phenolic moieties within the catechin molecule remains the same during the reaction of catechin with epichlorohydrin because catechin derivatives with three methyloxirane functions on average were mostly obtained.

The synthesized GEC was tested in epoxy resins formulation and exhibited good thermal properties in comparison with an epoxy resin based on pure commercial DGEBA. 
This work shows the feasibility of epoxy resin formulation based on flavonoid building blocks. The next step will be to carry out an alternative two-step chemical synthesis (allylation followed by epoxidation) of glycidylether derivatives to overcome eventually the incomplete functionalization of the phenolic hydroxyls groups of catechin observed with epichlorohydrin. Afterward, the synthesis of epoxy resin with the corresponding polymerized forms, that is, condensed tannins as starting materials, will be performed. Nevertheless, it already opens up new prospects on the valorization of industrial byproducts rich in tannins such as grape pomaces, wood, or algae. These renewable phenolic resources seem to be promising for the replacement of BPA in epoxy resin formulation. In comparison to lignin, tannins are water-soluble extractible materials, usually less polymerized macromolecules and with a higher content of free phenolic hydroxyl groups, offering a great potential of functionalization and network formation.

The authors are grateful to the Carnot CED2 Institute in Montpellier and to the Innobat Company for their financial support. The authors thank the Nanoledge Chemicals Company for supplying DGEBA and Epamine PC19, and for their assistance in formulation. The authors also thank Jean-marc Souquet (SPO, INRA, France), Jean-Claude Boulet (SPO, INRA, France), and Léna Saint-Macary (Innobat, France) for their help on analyses, as well as Andrew Burns for its assistance in english correction.

\section{REFERENCES AND NOTES}

1 European Parliament Council. Directive 2002/95/EC Restriction of the use of certain Hazardous Substances in Electrical and Electronic Equipment 2002.

2 European Parliament Council. Directive 2002/96/EC Waste Electrical and Electronic Equipment 2002.

3 European Parliament Council. Directive 2000/53/EC End-ofLife Vehicles 2000.

4 European Parliament Council. Directive 2000/60/EC Water Framework Directive 2000.

5 Council. Directive 1967/548/EC Dangerous Substances Directive 1967.

6 Cao, X. L.; Corriveau, J.; Popovic, S. J Agric Food Chem 2009, 57, 1307-1311.

7 Joskow, R.; Barr, D. B.; Barr, J. R.; Calafat, A. M.; Needham, L. L.; Rubin, C. J Am Dental Assoc 2006, 137, 353-362.

8 Lopez-Espinosa, M. J.; Granada, A.; Araque, P.; MolinaMolina, J. M.; Puertollano, M. C.; Rivas, A.; Fernandez, M.; Cerrillo, I.; Olea-Serrano, M. F.; Lopez, C.; Olea, N. Food Addit Contam Part A 2007, 24, 95-102.

9 Maragou, N. C.; Makri, A.; Lampi, E. N.; Thomaidis, N. S.; Koupparis, M. A. Food Addit Contam Part A 2008, 25, 373-383.

10 Matsumoto, H.; Adachi, S.; Suzuki, Y. Arch Environ Contam Toxicol 2005, 48, 459-466.

11 Kuruto-Niwa, R.; Tateoka, Y.; Usuki, Y.; Nozawa, R. Chemosphere 2007, 66, 1160-1164.
12 Vom Saal, F. S.; Hugues, C. Environ Health Perspect 2005, $113,926-933$.

13 Wolff, M. S.; Teitelbaum, S. L.; Windham, G.; Pinney, S. M.; Britton, J. A.; Chelimo, C.; Godbold, J.; Biro, F.; Kushi, L. H.; Pfeiffer, C. M.; Calafat, A. M. Environ Health Perspect 2007, $115,116-121$.

14 Dorey, C. K. Chemical Legacy: Contamination of the Child; Greenpeace: London, 2003.

15 Cheng, J.; Chen, J.; Yang, W. T. Chin Chem Lett 2007, 18, 469-472.

16 Asada, C.; Nakamura, Y.; Kobayashi, F. Biochem Eng J 2005, 23, 131-137.

17 Kishi, H.; Fujita, A. Environ Eng Manag J 2008, 7, 517-523.

18 Kishi, H.; Fujita, A.; Miyazaki, H.; Matsuda, S.; Murakami, A. J Appl Polym Sci 2006, 102, 2285-2292.

19 Garnier, S.; Huang, Z.; Pizzi, A.; Huang, Z. Holz Roh Werkst 2001, 59, 46-46.

20 Garnier, S.; Pizzi, A. J Appl Polym Sci 2001, 81, 3220-3230.

21 Pizzi, A.; Stephanou, A. J Appl Polym Sci 1993, 50, 2105-2113.

22 Pizzi, A.; Tondi, G.; Pasch, H.; Celzard, A. J Appl Polym Sci 2008, 110, 1451-1456.

23 St. Clair, W. E. U.S. Patent 2,892,849, 1959.

24 Nouailhas, H.; Burguiere, C.; Caillol, S.; Boutevin, B.; Fulcrand, H.; Rapior, S. FR Patent 2,946,049, 2010.

25 Lee, H.; Neville, K. In Handbook of Epoxy Resins; McGrawHill Publishing Company, NY, 1967, pp 4.1-4.70.

26 Morreel, K.; Ralph, J.; Lu, F. C.; Goeminne, G.; Busson, R.; Herdewijn, P.; Goeman, J. L.; Van der Eycken, J.; Boerjan, W.; Messens, E. Plant Physiol 2004, 136, 4023-4036.

27 Maes, D.; Syngel, V. K.; Debenedetti, S.; De Kimpe, N. Tetrahedron 2006, 62, 4426-4429.

28 Lehrle, R. S.; Williams, R. J. Macromolecules 1994, 27, 3782-3789.

29 Jiang, B. B.; Hao, J. J.; Wang, W. Y.; Jiang, L. X.; Cai, X. X. Eur Polym J 2001, 37, 463-470.

30 Chiu, Y. C.; Chou, I. C.; Tseng, W. C.; Ma, C. C. M. Polym Degrad Stab 2008, 93, 668-676.

31 lijima, T.; Yoshioka, N.; Tomoi, M. Eur Polym J 1992, 28, 573-581.

32 Flory, J. P. Polymer 1979, 20, 1317-1320.

33 Gulino, D.; Galy, J.; Pascault, J. P.; Pham, O. T. Makromol Chem 1984, 185, 297-316.

34 Gulino, D.; Galy, J.; Pascault, J. P.; Tighzert, L.; Pham, O. T. Makromol Chem 1983, 184, 411-429.

35 Cren-Olive, C.; Wieruszeski, J. M.; Maes, E.; Rolando, C. Tetrahedron Lett 2002, 43, 4545-4549.

36 Cren-Olive, C.; Lebrun, S.; Hapiot, P.; Pinson, J.; Rolando, C. Tetrahedron Lett 2000, 41, 5847-5851.

37 Charlesworth, J. M. Polym Eng Sci 1988, 28, 230-236. 